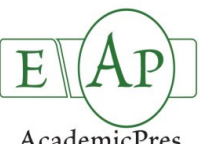

\title{
Bioactive Compounds, Antioxidant Activity and Color of Hydroponic Tomato Fruits at Different Stages of Ripening
}

\author{
Violeta NOUR ${ }^{1 *}$, Mira E. IONICA ${ }^{1}$, Ion TRANDAFIR ${ }^{2}$ \\ ${ }^{1}$ University of Craiova, Faculty of Horticulture, 13 A.I. Cuza, 200585 Craiova, \\ Romania;vionour@central.ucv.ro;miraelena29@yahoo.com \\ ${ }^{2}$ University of Craiova, Faculty of Mathematics and Natural Sciences, 107 Calea Bucuresti, 200529 Craiova, Romania; nelutrandafir@yahoo.com
}

\begin{abstract}
This experiment was carried out in order to study the simultaneous effect of on-vine ripening and examined cultivars on fruit quality, color development and antioxidant content in two different types of tomatoes. 'Admiro' and 'Komet' (normal average fruit weight) and 'Cheramy' (cherry type) cultivars grown in hydroponic culture were used. Dry matter, soluble solids, titratable acidity, ascorbic acid, lycopene, $\beta$-carotene, total phenolic, total flavonoid content and hydrophilic antioxidant activity were measured in six ripening stages. Color of fruits was determined by CIELab system. The $\mathrm{L}^{*}, \mathrm{a}^{*}, \mathrm{~b}^{*}$ values were used to calculate hue angle $\left(\mathrm{h}^{\circ}\right)$, chroma $\left(\mathrm{C}^{*}\right)$ and $\mathrm{a}^{*}$ to $\mathrm{b}^{*}$ ratio. In all analysed cultivars total phenolic content increased as ripening progressed, reached the maximum at the pink stage and subsequently declined, while the trend of ascorbic acid was cultivar dependent. DPPH radical scavenging activity showed significant moderately strong positive correlations with total phenolics and ascorbic acid. The content of $\beta$-carotene increased constantly during ripening while lycopene content registered a sharp rise, especially in the last stage of ripening when $47.2 \%$ of the lycopene content was accumulated. During ripening the lightness $\left(\mathrm{L}^{*}\right)$ decreased because tomato fruit colour became darker while the ratio of red to green colour increased as a result of carotenoids synthesis. Among color indexes, hue angle $\left(h^{\circ}\right)$ was best correlated with lycopene content $(r=-0.758)$, followed by $\mathrm{a}^{*}(\mathrm{r}=0.748), \mathrm{C}^{*}(\mathrm{r}=0.708)$ and $\mathrm{a}^{*} / \mathrm{b}^{*}(\mathrm{r}=0.683)$. Better correlations were established between main carotenoids content (lycopene $+\beta$-carotene) and each of the color indexes.
\end{abstract}

Keywords: lycopene, $\beta$-carotene, ascorbic acid, phenolics, flavonoids, color indexes, cultivars

\section{Introduction}

Tomato (Lycopersicon esculentum Mill.) is one of the most widely consumed vegetable food crops worldwide. Tomato is commonly grown either in the field or under greenhouse conditions but it is also one of the most important horticultural crops grown in hydroponics (Fanasca et al., 2006).

Besides sensory qualities and nutritional value, tomatoes play a key role in human diet, being recognized as a health promoting food. Several epidemiological studies have established a link between consuming tomato and its products and reduced risk of various maladies like obesity, hyperglycemic and hypercholesterolemic attributes, cancer and cardiovascular diseases (Perveen et al., 2015). The beneficial effects on human health have been mainly attributed to their rich composition in bioactive compounds such as carotenoids, ascorbic acid, tocopherols, phenolic acids and flavonoids and to the synergistic effects among these different classes of antioxidants (Kuti and Konuru, 2005; Helyes and Lugasi, 2006; Ilahy et al., 2011; Vinha et al., 2014). Their activity is based on scavenging free radicals and preventing lipid oxidation (Lee et al., 2004; Radzevičius et al., 2009) thereby increasing cell protection from DNA damage by oxidant species (Garcia-Valverde $e$ t al., 2013).

Tomatoes and related products are a major source of dietary carotenoids in the human diet which are synthesized massively during fruit ripening (Guil-Guerrero and Reboloso Fuentes, 2009). The two main carotenoids in tomato fruits are lycopene $(\psi, \psi$-carotene), which imparts the red colour of tomato, and $\beta$ carotene, which accounts for approximately $7 \%$ of tomato carotenoid content (Kuti and Konuru, 2005). Although it has no provitamin A activity, lycopene is a potent lipophilic antioxidant, with greater antioxidant activity than other carotenoids, which have been demonstrated by in vitro and in vivo studies to possess antioxidant, hypolipidemic, and anticarcinogenic activities (Viuda-Martos et al., 2014).

Tomato fruits are also rich in phenolic compounds, which are considered as potentially health-promoting substances due to their anti-oxidative, anti-cancer, anti-diabetes and cardiovascular protective effects. Tomatoes contain quercetin, naringenin, rutin and chlorogenic acid as the main phenolic compounds 
(Martinez-Valverde et al., 2002) which, along with ascorbic acid, are determinants of the hydrophilic antioxidant activity (HAA) (Garcia-Valverde et al., 2013).

The content of health-promoting bioactive compounds in fresh tomatoes is influenced by numerous factors, including genetic ones such as cultivar or variety, environmental factors light, temperature, air composition, mineral nutrition, growth medium) and cultural practices (training system, irrigation system), and ripening stage of the fruit at harvest (Helyes and Lugasi, 2006; Garcia-Valverde et al., 2013).

Depending on consumer and market requirements, tomatoes are harvested at different stages of ripening from breaking to red colour (Wold et al., 2004).

During ripening, various biochemical, physiological and structural processes take place including degradation of chlorophylls, synthesis and storage of carotenoids (mainly lycopene and $\beta$-carotene) and aromatic compounds, alterations in organic acid metabolism, a softening of the fruit tissue which occur in conjunction with an increase in $\mathrm{CO}_{2}$ production (the respiratory climacteric) and an increase in ethylene production by the fruit (Ilahy et al., 2011; Domínguez et al., 2012). The amount of other important antioxidants, such as ascorbic acid and phenolics, is also variable during tomato ripening. Ascorbic acid content might increase with ripening due to enhanced respiration (Garcia-Valverde et al., 2013) while phenolic compounds are synthesized by tomatoes because of their involvement in the defense mechanisms against reactive oxygen species, which are produced in great quantities during the climacteric crisis. All these events determine major changes in texture, color, flavor, and aroma but also greatly affect the antioxidant activity of tomato fruits (Pék et al., 2010).

Contribution of HAA and LAA to total antioxidant activity varies during tomatoes ripening. Kotíková et al. (2011) found that HAA has far more significant impact on total antioxidant activity (83\%) as compared with LAA. HAA was increasing during all ripening stages and was strongly correlated with ascorbic acid content. Nour et al. (2014) observed a continuous increase of HAA during development and ripening of tomato fruits until the pink or light red stages where, depending on the cultivar, HAA reached maximum values and then declined significantly. Ilahy et al. (2011) recorded the highest HAA in tomato fruits at the green stage of ripening and the lowest value at the red-ripe stage.

Several previous studies have investigated variation in phytochemical composition in different tomato genotypes, as a function of ripening degree (Thompson et al., 2000; Raffo et al., 2002; Kotíková et al., 2009; Radzevičius et al., 2009; Ilahy et al., 2011; Pék et al., 2011; Opara et al., 2012; Hdider et al., 2013; Aghofack-Nguemezi and Schwab, 2015) but no such reports on tomatoes grown in hydroponics. The production of hydroponic tomatoes has increased significantly during the last few years (Aljouni $e t$ al., 2001). The cultivation of plant material in hydroponics ensures reproducibility by uniformity of growth conditions and homogeneity of nutrient concentrations. This kind of cultivation, carried out under controlled conditions, also eliminates problems linked to the disinfection of soil and balance of nutrients encountered in natural soil due to the nonhomogeneous distribution of nutrients (Sgherri et al., 2010). Lycopene and other antioxidants content in hydroponic tomatoes, which represent an important and growing section in the tomato industry, has not been well investigated.
The present study aimed to investigate the trends related to the effect of genotype and on-vine ripening on the major bioactive compounds (lycopene, $\beta$-carotene, total phenolics, total flavonoids and ascorbic acid) and hydrophilic antioxidant activity occurring in one cherry type and two standard tomato cultivars grown simultaneously in hydroponics. There were also investigated correlations between the content of antioxidant compounds, hydrophilic antioxidant activity and the color evolution of the tomato fruit surface.

\section{Materials and Methods}

Tomatosamples

The tomato samples were cultivated on coconut fiber in a commercial hydroponic greenhouse located at Gradinari, Oltenia

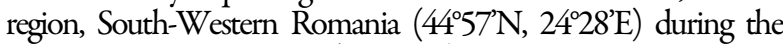
2014 spring growing season (May-July). Two indeterminate roundtype tomato hybrids ('Admiro', 'Komet') and one indeterminate cherry type tomato hybrid ('Cheramy') were investigated.

All hybrids were grown simultaneously, subjected to identical cultural practices and environmental conditions, in order to minimize the influence of pre-harvest factors on genotype-related variability of hydroponic tomatoes.

In order to study the influence of on-vine ripening on bioactive compounds content and antioxidant activity, tomatoes were harvested at six different ripening stages (mature green, breaker, turning, pink, red and deep-red) according to Yamaguchi (1983). For each ripening stage, at least $1 \mathrm{~kg}$ of tomato fruit sample was randomly harvested. After collecting, the fruits were washed, blotted with a paper towel, packed in a portable refrigerator and they were transported to the laboratory. Color measurements were performed then fruit samples were cut into pieces and ground to a homogeneous puree using a model $7011 \mathrm{HS}$ Waring blender. From this puree, several sub-samples were taken on triplicate to measure dry matter content, soluble solids content and titratable acidity whereas the remaining was frozen at $-20^{\circ} \mathrm{C}$ and used to determine lycopene, $\beta$-carotene, total phenolics, total flavonoids, ascorbic acid, as well as hydrophilic antioxidant activity. Experiments were performed three independent times and all analyses were conducted in triplicate. Error bars represent standard deviations from the three experiments performed in triplicate.

\section{Chemicals andreagents}

Folin-Ciocalteu reagent (2 N), 6-hydroxy-2,5,7,8tetramethylchroman-2-carboxylic acid (Trolox), HPLC grade acetonitrile, acetone, $\mathrm{n}$-hexane and methanol were purchased from Merk (Germany). Gallic acid (99\% purity), anhydrous sodium carbonate ( $99 \%$ purity), aluminium nitrate, potassium acetate, quercetin and 2,2-diphenyl-1-picrylhydrazyl (DPPH, 90\% purity) were from Sigma-Aldrich (Germany). Ultrapure water was obtained from a Milli-Q water purification system (TGI Pure Water Systems, USA).

Determination of dry matter content, soluble solids content and titratable acidity

Dry matter content was determined by the following gravimetric assay: a known amount $(5 \mathrm{~g})$ of each fresh tomato sample was heated in an electric-oven (Memmert, Germany) at $105^{\circ} \mathrm{C}$, until the complete loss of moisture and constant weight achieved.

The soluble solids content was determined by placing a drop of filtered puree on the prism of a digital refractometer with 
406

automatic temperature compensation (Euromex, Arnhem, The Netherlands) and expressed as ${ }^{\circ}$ Brix at $20^{\circ} \mathrm{C}$. Titratable acidity (\% as citric acid) was measured by a direct titration method (AOAC, 2005). Briefly, the homogenized sample was mixed with distilled water and titrated with $0.1 \mathrm{~N} \mathrm{NaOH}$ solution using phenolphthalein as indicator.

\section{Determination of ascorbic acid}

Ascorbic acid was analyzed by RP-HPLC on a Finningan Surveyor Plus system (Thermo Electron Corporation, San Jose, CA, USA) equipped with a diode array detector. Five grams of frozen tomato homogenate were mixed and diluted to $100 \mathrm{~mL}$ with $0.1 \mathrm{~N}$ $\mathrm{HCl}$ and the mixture was kept at room temperature for $30 \mathrm{~min}$. After the suspension had been centrifuged ( $4200 \mathrm{rpm}, 10 \mathrm{~min}$ ), the supernatant was filtered through a $0.2 \mu \mathrm{m}$ pore size filter. For the separation a Hypersil Gold aQ column (25 cm x $4.6 \mathrm{~mm}$ ), termostated at $10^{\circ} \mathrm{C}$, was used. The mobile phase was a $50 \mathrm{mM}$ water solution of $\mathrm{KH}_{2} \mathrm{PO}_{4}$ buffer adjusted to $\mathrm{pH} 2.8$ with orthophosphoric acid. A mobile phase flow rate of $0.7 \mathrm{~mL} / \mathrm{min}$ was used, with detection of analytes at $254 \mathrm{~nm}$. Ascorbic acid content was expressed as $\mathrm{mg} / \mathrm{kg}$ fresh weight ( $\mathrm{fw}$ ).

\section{Determination oflycopene and $\beta$-carotene}

Lycopene and $\beta$-carotene were determined according to the method of Nagata and Yamashita (1992). Briefly, $1.0 \mathrm{~g}$ of tomato puree was extracted with $16 \mathrm{~mL}$ of acetone-hexane $(2: 3, \mathrm{v} / \mathrm{v})$ solvent and, after $15 \mathrm{~min}$ of shaking in a test tube and phase separation, the absorbance of the hexane layer was measured in a 1 $\mathrm{cm}$ path length quartz cuvette at $663,645,505$, and $453 \mathrm{~nm}$ using a UV-Vis spectrophotometer (Varian Cary $50 \mathrm{UV}-\mathrm{Vis}$, Varian Co., USA). The contents of lycopene and $\beta$-carotene were calculated according to the following equations: Lycopene $(\mathrm{mg} / 100 \mathrm{~mL})=-0.0458 \times \mathrm{A}_{663}+0.204 \times \mathrm{A}_{645}+0.372 \times \mathrm{A}_{505}-$ $0.0806 \times \mathrm{A}_{453} ; \beta$-Carotene $(\mathrm{mg} / 100 \mathrm{~mL})=0.216 \times \mathrm{A}_{663}-1.220$ $\times \mathrm{A}_{645}-0.304 \times \mathrm{A}_{505}+0.452 \times \mathrm{A}_{453}$. The results were expressed in $\mathrm{mg} / \mathrm{kg}$ fw.

\section{Determination of total phenolics}

Total phenolic content was quantified spectrophotometrically using the Folin-Ciocalteau reagent according to the method described by Singleton and Rossi (1965). Gallic acid was used for the construction of the calibration curve. Five grams of tomato puree were mixed with $10 \mathrm{~mL}$ of methanol containing $0.5 \%$ hydrochloric acid and sonicated during $50 \mathrm{~min}$ at room temperature. After extraction, samples were centrifuged for $5 \mathrm{~min}$ at $4200 \mathrm{rpm}$ and supernatants were filtered through $0.45 \mu \mathrm{m}$ polyamide membranes. $100 \mu \mathrm{L}$ of each tomato methanolic extract were mixed with $5 \mathrm{~mL}$ of distilled water and $500 \mu \mathrm{L}$ of FolinCiocalteau reagent. After a $5 \mathrm{~min}$ reaction time, $1.5 \mathrm{~mL}$ of $20 \%$ sodium carbonate solution was added. The reaction mixture was diluted with distilled water to a final volume of $10 \mathrm{~mL}$. The same procedure was also applied to the standard solutions of gallic acid. The absorbance at $765 \mathrm{~nm}$ of each mixture was measured on a Varian Cary 50 UV-Vis spectrophotometer (Varian Co., USA) after incubation for $30 \mathrm{~min}$ at $40^{\circ} \mathrm{C}$. Results were reported in $\mathrm{mg}$ of gallic acid equivalents (GAE) $/ \mathrm{kg} \mathrm{fw}$.

\section{Determination of total flavonoids}

Total flavonoid content was determined as described by Mohammadzadeh et al. (2007). Briefly, $0.5 \mathrm{~mL}$ of each tomato methanolic extract was diluted with methanol (1:10) and mixed in a test tube with $0.1 \mathrm{~mL}$ of $10 \%$ aluminum nitrate, $0.1 \mathrm{~mL}$ of $1 \mathrm{M}$ aqueous potassium acetate and $4.3 \mathrm{~mL}$ methanol. After $40 \mathrm{~min}$ reaction time, the absorbance of the mixture was measured at 415 nm using an Evolution 600 UV-Vis spectrophotometer (Thermo Scientific, USA). Quercetin was used for preparing the standard curve $(0-100 \mathrm{mg} / \mathrm{L})$. Total flavonoid content was expressed as milligrams of quercetin equivalents $(\mathrm{QE}) / \mathrm{kg} f \mathrm{w}$.

\section{Determination of hydrophylic antioxidant activity}

The hydrophilic radical scavenging activity was evaluated in methanolic extracts using the DPPH (2,2-diphenyl-1-picrylhydrazyl) assay as described by Oliveira et al. (2008), with some modifications. The extraction of samples was made according to the same protocol as described for total phenolic content. Each methanol tomato extract $(50 \mu \mathrm{L})$ was mixed with $3 \mathrm{~mL}$ of methanolic solution containing $0.004 \%(\mathrm{v} / \mathrm{v}) \mathrm{DPPH}$. The mixture was shaken vigorously and kept in the dark for $30 \mathrm{~min}$. The absorbance was then read at $517 \mathrm{~nm}$ using an Evolution 600 UV-Vis spectrophotometer (Thermo Scientific, USA). The radical scavenging activity was calculated as a percentage of DPPH inhibition using the following formula: DPPH scavenging activity $(\%)=\left[1-\mathrm{A}_{\mathrm{s}} / \mathrm{A}_{\mathrm{DPPH}}\right] \times 100$ where $\mathrm{As}_{\mathrm{s}}$ represents the absorbance of the sample extract with DPPH and ADPPH is the absorbance of the DPPH solution without sample. Trolox (6-hydroxy-2,5,7,8tetramethylchromane-2-carboxylic) was used as a standard and $80 \%$ methanol was used as a blank. Results were expressed in $\mathrm{mmol}$ Trolox $/ \mathrm{kgfw}$.

\section{Colormeasurements}

Color space coordinates $\left(L^{*}, a^{*}, b^{*}\right)$ were taken from each tomato at the equatorial region using an Evolution 600 spectrophotometer (Thermo Scientific, USA) equiped with DRA-EV-600 diffuse Reflectance Accessory and the VL ColorCalc software. These values correspond to the degree of lightness $\left(\mathrm{L}^{*}\right)$ and the degree of red $\left(\right.$ when $\left.\mathrm{a}^{*}>0\right)$, green $\left(\right.$ when $\mathrm{a}^{*}<$ 0 ), yellow (when $b^{*}>0$ ), and blue (when $b^{*}<0$ ) colour. The spectrophotometer was calibrated against standard white plate and checked for calibration between measurements. For each sample at least five measurements were performed at different positions. Hue angle $\left(\mathrm{h}^{\circ}\right.$, colour shade) was calculated from $\arctan \left(\mathrm{b}^{*} / \mathrm{a}^{*}\right)$ while the parameter chroma ( $\mathrm{C}^{*}$, colour saturation) was calculated as $\left(\mathrm{a}^{* 2}+\mathrm{b}^{* 2}\right)^{1 / 2}$.

\section{Statistical analysis}

Results of all analysis were expressed as mean value \pm standard deviation. Data were statistically analyzed using Statgraphics Centurion XVI software (StatPoint Technologies, Warrenton, VA, USA). Analysis of variance (ANOVA) was conducted, followed by LSD multiple range test for multiple comparisons to establish significant differences between means with a confidence level of 95\%. Correlations were estimated using Pearson's correlation coefficient $(\mathrm{r})$.

\section{Results and Discussion}

The dry matter contents of the investigated tomato cultivars at the six different ripening stages are shown in Fig. 1.

Statistically significant differences were found among cultivars, the cherry type cultivar showing significantly higher values at the deep-red stage $(8.45 \%)$ than the other standard tomato varieties ( $4.81 \%$ and $5.98 \%$ for 'Komet' and 'Admiro' cultivars respectively). 


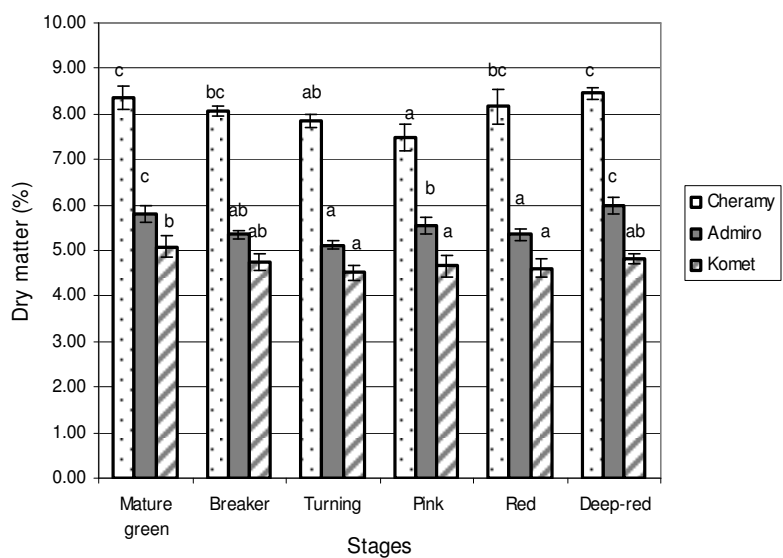

Fig. 1. Variation of dry matter content of tomato fruits during ripening. Different ripeness stages within the same cultivar have been compared Bars for the same cultivar showing different letters are significantly different $(\mathrm{p}<0.05)$

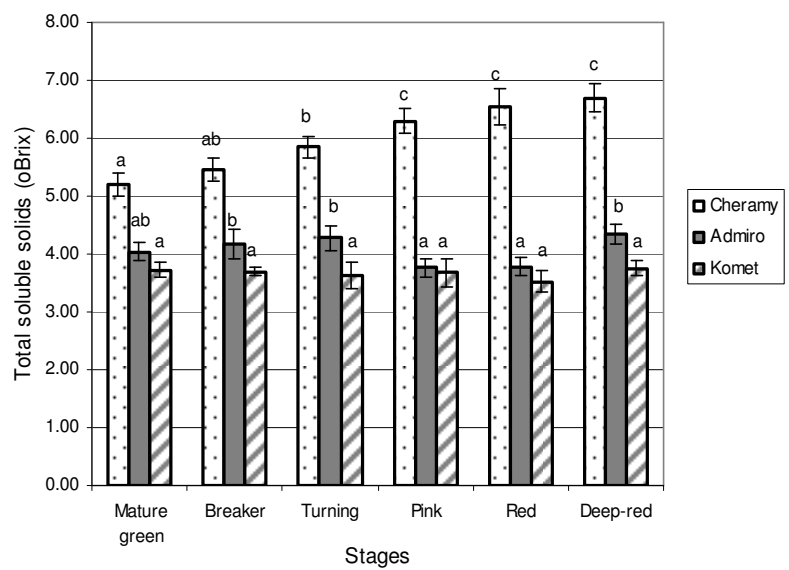

Fig. 2. Variation of total soluble solids content of tomato fruits during ripening. Different ripeness stages within the same cultivar have been compared

Bars for the same cultivar showing different letters are significantly different $(\mathrm{p}<0.05)$

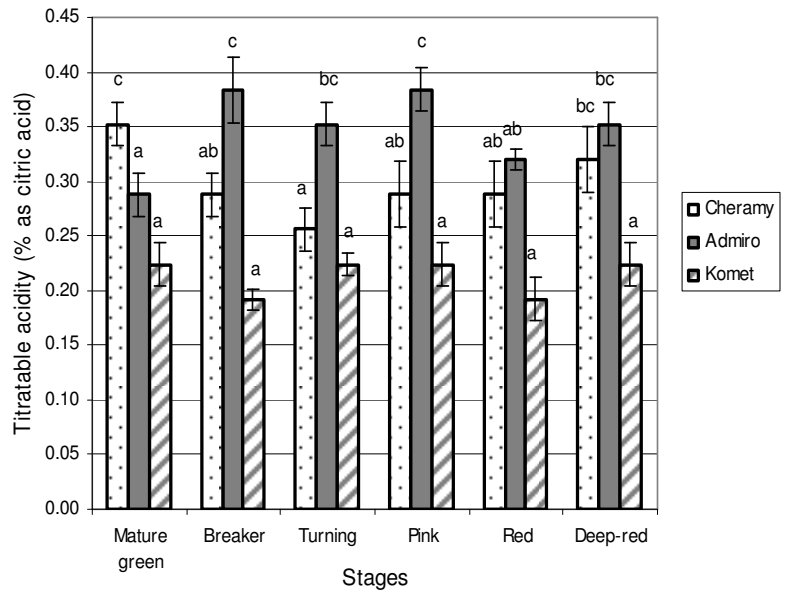

Fig. 3. Variation of titratable acidity of tomato fruits during ripening. Different ripeness stages within the same cultivar have been compared Bars for the same cultivar showing differentletters are significanty different $(\mathrm{p}<0.05)$

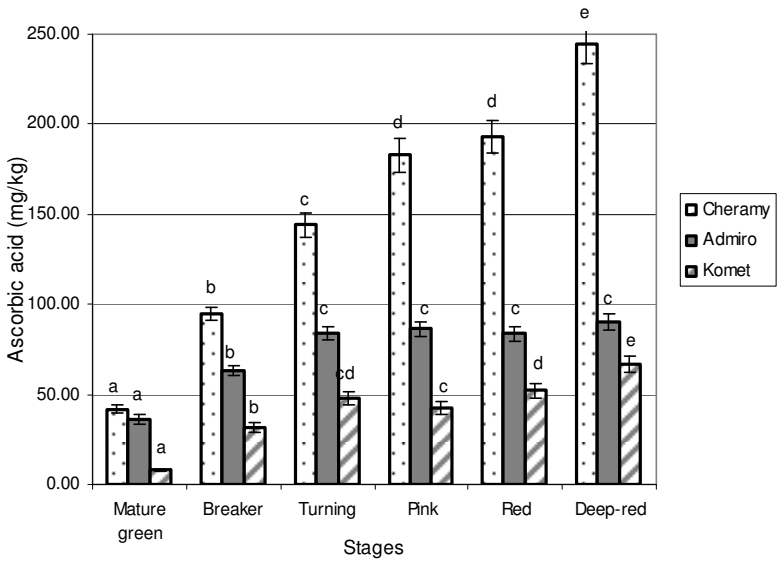

Fig. 4. Variation of ascorbic acid content of tomato fruits during ripening. Different ripeness stages within the same cultivar have been compared Bars for the same cultivar showing differentletters are significanty different $(\mathrm{p}<0.05)$

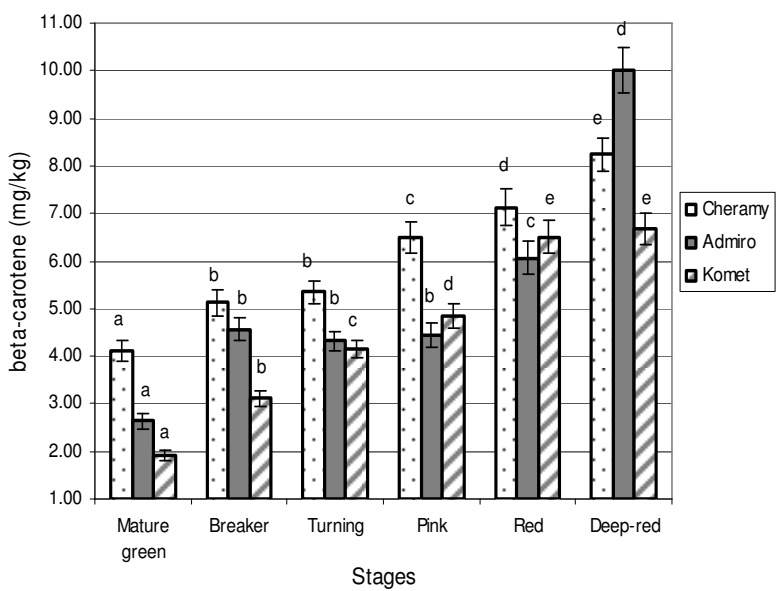

Fig. 5. Variation of $\beta$-carotene content of tomato fruits during ripening. Different ripeness stages within the same cultivar have been compared Bars for the same cultivar showing differentletters are significandy different $(p<0.05)$

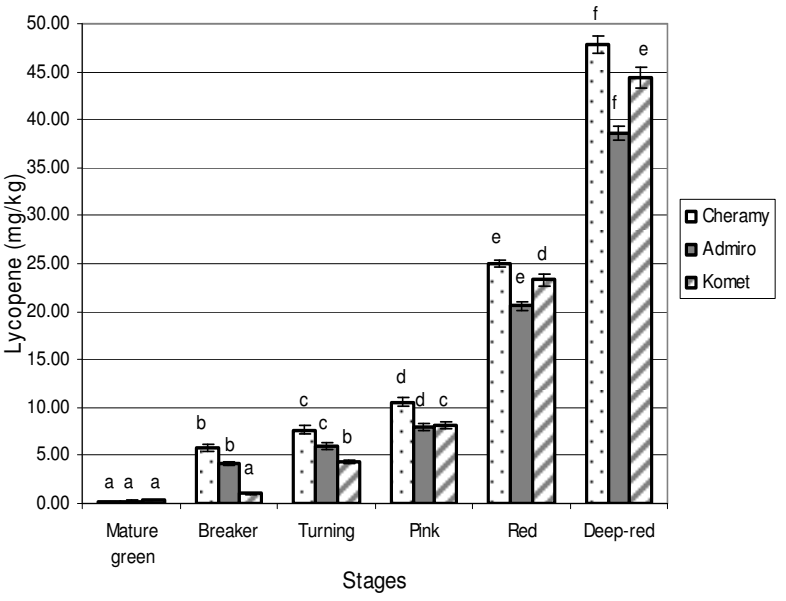

Fig. 6. Variation of lycopene content of tomato fruits during ripening. Different ripeness stages within the same cultivar have been compared Bars for the same cultivar showing differentletters are significanty different $(\mathrm{p}<0.05)$ 
408

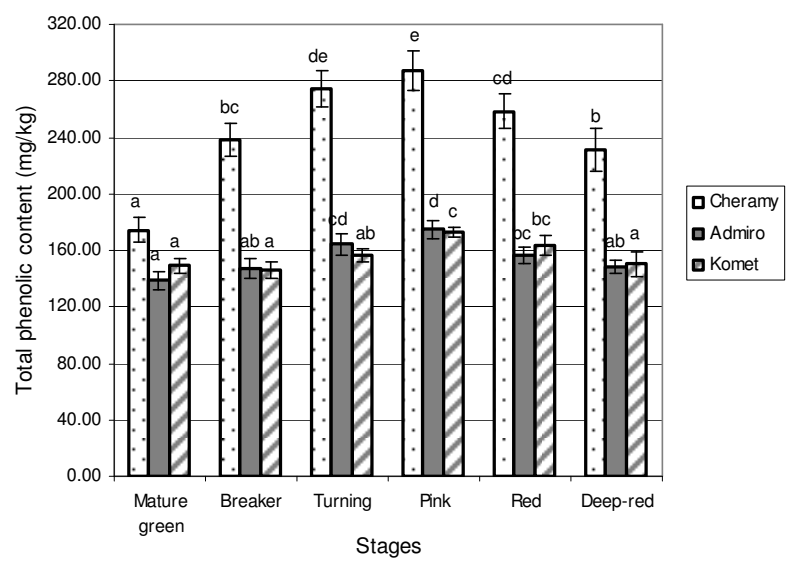

Fig. 7. Variation of total phenolic content of tomato fruits during ripening. Different ripeness stages within the same cultivar have been compared

Bars for the same cultivar showing differentletters are significantly different $(\mathrm{p}<0.05)$

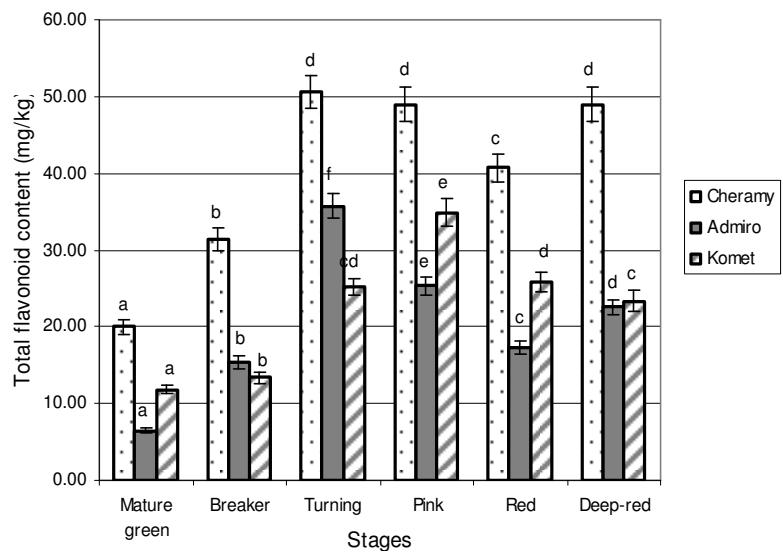

Fig. 8. Variation of total flavonoid content of tomato fruits during ripening. Different ripeness stages within the same cultivar have been compared

Bars for the same cultivar showing different letters are significantly different $(\mathrm{p}<0.05)$

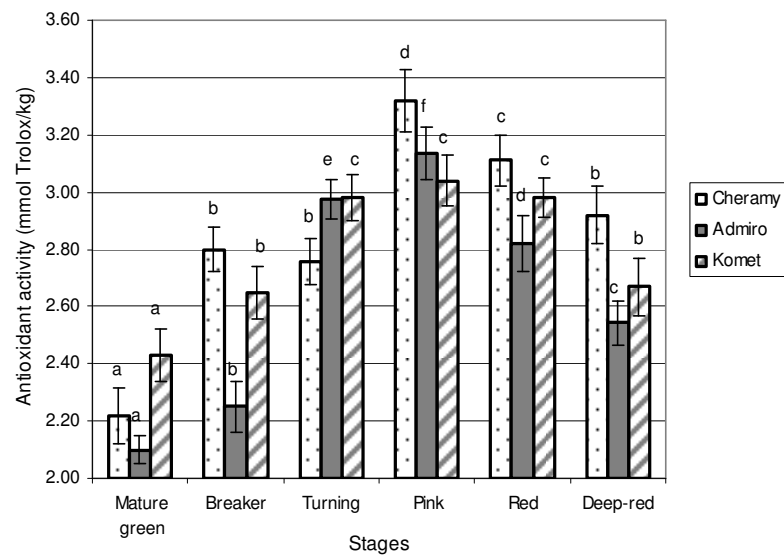

Fig. 9. Variation of hydrophilic antioxidant activity of tomato fruits during ripening. Different ripeness stages within the same cultivar have been compared

Bars for the same cultivar showing different letters are significanty different $(\mathrm{p}<0.05)$
During ripening, the fruit dry matter content registered a decrease from mature green to the turning or pink stage, depending on the cultivar, followed by a slight increment in the last two stages, as reported in previous studies (Helyes and Lugasi, 2006; Opara et al., 2012; Nour etal.,2014).

At the deep red stage soluble solids content was determined between $3.75 \%$ ('Komet') and 6.70\% ('Cheramy'), values in accordance with previous studies on tomatoes grown in soilless culture (Fanasca et al., 2006). As regards the evolution during ripening, at 'Komet' cultivar soluble solid content remained practically constant in the last four stages of ripening while in 'Cheramy' cultivar soluble solid content increased steadily, although no statistical differences were observed between pink, red and deepred tomatoes (Fig. 2).

Titratable acidy (as citric acid) ranged from $0.22 \%$ ('Komet') and $0.32 \%$ ('Cheramy') at the deep-red stage, values similar to the results reported by Fanasca et al. (2006) for standard tomatoes grown in soilless culture. No clear trend of titratable acidity was observed during ripening in the different cultivars studied (Fig. 3).

In 'Cheramy' and 'Komet' cultivars ascorbic acid content grew up significantly evenly during ripening (Fig. 4), reaching maximum values at the deep-red stage while in the fruits of 'Admiro' cultivar ascorbic acid content increased significantly from mature green to turning and was kept constant in the last stages. This tendencies do not agree with that observed by Nour et al. (2014), who found that ascorbic acid reached its maximum level at the pink or red stage of fruit ripening, depending on the cultivar, and then declined significantly or by Cano et al. (2003) who found that ascorbic acid remained practically constant in the first three ripening stages, increasing slightly in the last stage when the fruit was fully ripe. Ilahy et al. (2011) found also that total vitamin C content during ripening was genotype dependent, the highest amount being recorded at the orange-red ripening stage in some cultivars $(220-333 \mathrm{mg} / \mathrm{kg} \mathrm{fw})$, but at the green-orange and red-ripe stages for others. However, other authors (Periago et al., 2009; Kotiková et al., 2011) have also observed a significant increase of ascorbic acid content during ripening. These different variations have been noted by other authors and have been assigned to varietal, environmental and agronomical factors.

All along the ripening process 'Cheramy' cultivar showed significantly higher ascorbic acid content than the other tomato cultivars, i.e. between $41.96 \mathrm{mg} / \mathrm{kg}$ fw (mature green) and 244.26 $\mathrm{mg} / \mathrm{kg} \mathrm{fw}$ (deep red). In general, these ascorbic acid values were in accordance with those reported by Garcia-Valverde et al. (2013) who found from $2.79 \mathrm{mg} / \mathrm{kg} \mathrm{fw}$ (breaker) to $297.62 \mathrm{mg} / \mathrm{kg} \mathrm{fw}$ (red) in 'Cherry Pera' cultivar. However, higher values ranging from 378.8 to $441.5 \mathrm{mg} / \mathrm{kg}$ fw were reported by Fanasca et al. (2006) in standard tomato cultivars grown in soilless culture.

The changes in $\beta$-carotene content during ripening process are showed in Fig. 5. The content of this carotenoid increased constantly during ripening in all analysed tomato cultivars. This is in accordance with other authors, who observed a constant increase in $\beta$-carotene content as ripening progressed (Radzevičius et al., 2009; Ilahy et al., 2011). However some previous studies have reported that $\beta$ carotene content increased in the earlier ripening stages and then decreased (Cano et al., 2003) while others found no statistical differences between breaker, pink and red tomatoes or no consistent pattern of change during ripening (Garcia-Valverde et al., 2013).

These conflicting results regarding the accumulation of $\beta$ carotene during fruit ripening observed by many authors (Egea $e t$ al., 2009) were assigned either to the different growing conditions and 
Table 1. Color parameters $\left(\mathrm{L}^{*}, \mathrm{a}^{*}, \mathrm{~b}^{*}\right)$ and indexes $\left(\mathrm{h}^{\circ}, \mathrm{C}\right)$ of tomato fruits at different ripeness stages

\begin{tabular}{|c|c|c|c|c|c|c|}
\hline \multirow[b]{2}{*}{ Cultivar } & \multicolumn{6}{|c|}{ Stages } \\
\hline & Mature green & Breaker & Turning & Pink & Red & Deep-red \\
\hline \multicolumn{7}{|c|}{ Colour lightness $\left(\mathrm{L}^{*}\right)$} \\
\hline 'Cheramy' & $54.50 \pm 2.32$ & $42.00 \pm 3.88$ & $54.50 \pm 3.98$ & $56.20 \pm 3.77$ & $48.10 \pm 3.11$ & $44.10 \pm 2.88$ \\
\hline 'Admiro' & $64.60 \pm 1.89$ & $62.40 \pm 4.22$ & $81.30 \pm 4.66$ & $49.50 \pm 3.12$ & $46.50 \pm 2.98$ & $42.80 \pm 3.22$ \\
\hline 'Komet' & $58.30 \pm 2.55$ & $60.90 \pm 3.66$ & $62.20 \pm 4.45$ & $54.80 \pm 4.33$ & $48.00 \pm 3.76$ & $46.70 \pm 4.12$ \\
\hline \multicolumn{7}{|c|}{ Colour index $\left(\mathrm{a}^{*}\right)$} \\
\hline 'Cheramy' & $-1.80 \pm 0.12$ & $5.80 \pm 0.33$ & $21.60 \pm 1.23$ & $23.00 \pm 1.09$ & $26.90 \pm 1.40$ & $29.90 \pm 1.61$ \\
\hline 'Admiro' & $-0.80 \pm 0.15$ & $8.70 \pm 0.42$ & $3.20 \pm 0.61$ & $27.90 \pm 1.35$ & $29.70 \pm 1.46$ & $28.40 \pm 1.43$ \\
\hline 'Komet' & $-0.70 \pm 0.21$ & $2.30 \pm 0.24$ & $12.70 \pm 0.70$ & $20.10 \pm 0.92$ & $26.30 \pm 1.33$ & $27.20 \pm 1.52$ \\
\hline \multicolumn{7}{|c|}{ Colour index $\left(\mathrm{b}^{*}\right)$} \\
\hline 'Cheramy' & $10.70 \pm 0.47$ & $15.80 \pm 0.72$ & $38.70 \pm 1.81$ & $42.20 \pm 2.26$ & $41.90 \pm 1.92$ & $40.90 \pm 1.82$ \\
\hline 'Admiro' & $22.50 \pm 1.22$ & $27.80 \pm 1.44$ & $29.10 \pm 1.66$ & $32.90 \pm 1.61$ & $35.80 \pm 1.82$ & $41.20 \pm 1.95$ \\
\hline 'Komet' & $24.00 \pm 1.13$ & $19.30 \pm 1.23$ & $20.20 \pm 1.25$ & $31.10 \pm 1.54$ & $32.90 \pm 1.67$ & $29.90 \pm 1.44$ \\
\hline \multicolumn{7}{|c|}{ Hue angle $\left(\mathrm{h}^{\circ}\right)$} \\
\hline 'Cheramy' & $80.46 \pm 1.04$ & $69.88 \pm 0.21$ & $60.87 \pm 0.25$ & $61.43 \pm 0.15$ & $57.33 \pm 0.16$ & $53.87 \pm 0.26$ \\
\hline 'Admiro' & $87.99 \pm 0.49$ & $72.66 \pm 0.06$ & $65.63 \pm 0.23$ & $59.73 \pm 0.02$ & $50.34 \pm 0.05$ & $45.45 \pm 0.08$ \\
\hline 'Komet' & $88.03 \pm 0.71$ & $83.89 \pm 0.29$ & $62.15 \pm 0.17$ & $57.15 \pm 0.10$ & $51.39 \pm 0.11$ & $47.74 \pm 0.22$ \\
\hline \multicolumn{7}{|c|}{ Chroma $\left(\mathrm{C}^{*}\right)$} \\
\hline 'Cheramy' & $10.85 \pm 0.44$ & $16.83 \pm 0.79$ & $44.32 \pm 2.18$ & $48.06 \pm 2.51$ & $49.79 \pm 2.37$ & $50.66 \pm 2.42$ \\
\hline 'Admiro' & $22.51 \pm 1.21$ & $29.13 \pm 1.50$ & $31.95 \pm 1.76$ & $43.14 \pm 2.10$ & $46.52 \pm 2.33$ & $50.04 \pm 2.42$ \\
\hline 'Komet' & $20.21 \pm 1.12$ & $21.42 \pm 1.25$ & $27.15 \pm 1.43$ & $37.03 \pm 1.79$ & $42.12 \pm 2.13$ & $40.42 \pm 2.09$ \\
\hline
\end{tabular}

Table 2. Pearson correlations $(r)$ between lycopene content, lycopene $+\beta$-carotene content and CIELab indices

\begin{tabular}{lllllll}
\hline & $\mathrm{L}^{*}$ & $\mathrm{a}^{*}$ & $\mathrm{~b}^{*}$ & $\mathrm{C}^{*}$ & $\mathrm{~h}^{\circ}$ & $\mathrm{a}^{*} / \mathrm{b}^{*}$ \\
\hline Lycopene content & -0.521 & 0.748 & 0.615 & 0.708 & -0.758 & 0.683 \\
& $(0.0264)$ & $(0.003)$ & $(0.0066)$ & $(0.001)$ & $(0.0003)$ & $(0.0018)$ \\
Lycopene + & -0.535 & 0.774 & 0.635 & 0.725 & 0.772 & $(0.693$ \\
$\beta$-carotene content & $(0.0221)$ & $(0.0002)$ & $(0.0047)$ & $(0.0007)$ & $(0.0002)$ & $(0.0014)$ \\
\hline${ }^{*}$ P-
\end{tabular}

${ }^{*} \mathrm{P}$-values (shown in parentheses) below 0.05 indicate statistically significant correlations at the $95.0 \%$ confidence level

cultivars or to the different functions of $\beta$-carotene in tomato fruits: firstly its involvement in the process of photosynthesis as a photoprotective antioxidant in the immature fruits and secondly, the contribution to the color of fruits at the final stages of fruit ripening.

The $\beta$-carotene content ranged from 1.93 (mature green 'Komet') to $10.2 \mathrm{mg} / \mathrm{kg}$ fw (deep red 'Admiro'). At the deep-red stage, its content was significantly higher in fruits of 'Admiro' cultivar $(10.2 \mathrm{mg} / \mathrm{kg})$, followed by 'Cheramy' $(8.24 \mathrm{mg} / \mathrm{kg})$ and 'Komet' $(6.67 \mathrm{mg} / \mathrm{kg})$, values which are consistent with those reported by Fanasca et al. (2006) for tomatoes grown in soilless culture.

The results on lycopene content showed a significant variation among the analysed tomato cultivars (Fig. 6). In the deep-red stage, the lycopene levels detected in the fruits ranged from $38.55 \mathrm{mg} / \mathrm{kg}$ fw ('Admiro') to $47.78 \mathrm{mg} / \mathrm{kg} \mathrm{fw}$ ('Cheramy'), values in in good agreement with the results published by previous studies, which have also demonstrated that there is a significant difference in the ability of tomatoes to synthesize carotenoids in relation to variety (Adalid $e t$ al, 2010; Frenich et al., 2005; Kuti and Konuru, 2005). However, Fanasca et al. (2006) found only between $18.59-27.96 \mathrm{mg} / \mathrm{kg}$ lycopene in standard tomatoes grown in soilless culture.

In all investigated tomato cultivars, the total amount of lycopene markedly increased during fruit ripening. The greatest increase was registered in the sixth stage of ripening when $47.2 \%$ of the lycopene content was accumulated. This result is in good agreement with that obtained by Helyes and Lugasi (2006) who found that $46 \%$ of the lycopene content was synthesized in this last stage.

Fig. 7 shows the evolution of total phenolics content of tomato fruits during ripening. Our results showed that although there were significant differences among total phenolic contents of the three cultivars studied, the patterns of variation were quite similar during fruit ripening. Total phenolics content increased during the first ripeness stages, reached a maximum value at the pink stage and then declined significantly during the last two stages. Helyes and Lugasi (2006) found also the highest phenolic content at the pink stage while other studies observed different patterns of variation in phenolic content between the studied cultivars, with peaks in the amount of phenols reached either at the orange-red or at the greenorange stage of ripening (Ilahy et al., 2011; Hdider $e t$ al., 2013). In the study of Garcia-Valverde et al. (2013) statistically significant differences were found between cultivars and ripening stages, but no clear trend was observed throughout ripening. Raffo et al. (2002) found also that total phenolics content showed slight, but significant, decreases at later stages of ripeness. They considered that the decrease of phenolic compounds in the fruit may be associated with the involvement of these compounds in the defense mechanisms against reactive oxygen species, which are produced in great quantities during the climacteric crisis as a consequence of the increase of the respiratory rate of the fruit.

At the deep red ripe stage the phenolic content of the fruits ranged from 148.21 to $231.45 \mathrm{mg} \mathrm{GAE} / \mathrm{kg}$ while at the pink stage the total phenolic content varied between 172.87 and $287.62 \mathrm{mg}$ $\mathrm{GAE} / \mathrm{kg}$. The fruits of cherry cultivar showed significantly higher values than the other cultivars, in which total phenolic contents were very similar (Fig. 7). Other studies reported also higher phenolic content in cherry type tomatoes compared to standard tomatoes (Kacjan-Marsic et al, 2011). Higher levels of total phenolic content in cherry tomatoes, compared to cultivars with larger fruits, are due to the higher skin to volume ratio of these varieties, which could enhance their phenolic content, since they occur mainly within the 
410

skin of the fruit (Stewart et al, 2000). In general, the phenolics values were comparable to that reported by Ilahy et al. (2011) while higher values ranging from 186.92 and $558.63 \mathrm{mg} \mathrm{GAE} / \mathrm{kg}$ fw were reported by Garcia-Valverde et al. (2013).

Little is known about physiological functions of flavonoids during ripening of tomato fruits but it is assumed that some specific flavonoids may play important roles in the regulation of climacteric ethylene biosynthesis while, in return, ethylene may stimulate their biosynthesis in the epicarp of tomato fruits during the ripening stages. It is hypothesized that naringenin and caffeic-acid-hexose may be part of natural mechanisms by which ripe tomato fruits prevent the over ripening when they are still attached to the mother plant (Aghofack-Nguemezi and Schwab, 2015).

As for phenolics, the results showed that the flavonoid content was significantly different between the various ripeness stages (Fig. 8). The pattern of variation in total flavonoids content was similar at all tomato cultivars, a statistically significant increase in the amount of flavonoids was evidenced at turning, followed by a decrease at the red stage and a final slight increase at the deep-red stage.

Hydrophilic antioxidant activity of tomato extracts followed the same trend in all cultivars, increasing from the mature green to the pink stage, afterwards decreasing significantly (Fig. 9). At the deepred stage, hydrophilic antioxidant activity ranged from $2.54 \mathrm{mM}$ Trolox/kg ('Admiro') to $2.92 \mathrm{mM}$ Trolox/kg ('Cheramy'), values comparable with those previously reported by Cano et al. (2003) in ripe tomato fruits. As other authors have found (Garcia-Valverde $e t$ al., 2013; Ilahy et al, 2011), hydrophilic antioxidant activity showed significant moderately strong positive correlations with total phenolic and ascorbic acid content $(\mathrm{p}<0.05 ; \mathrm{r}=0.570$ and $\mathrm{r}=0.516$, respectively).

A statistically significant stronger correlation was found between total phenolic content and ascorbic acid content in all cultivars $(\mathrm{r}=0.804 ; \mathrm{p}<0.05)$, a finding consistent with the results reported by Kotíková et al. (2011) and Garcia-Valverde et al. (2013).

Table 1 lists the levels of color parameters $\left(\mathrm{L}^{*}, \mathrm{a}^{*}, \mathrm{~b}^{*}\right)$ and CIELab indexes $\left(\mathrm{h}, \mathrm{C}^{*}\right)$ of tomato fruits at different ripening stages. During fruit ripening color parameter $\mathrm{a}^{*}$ had a sharp increase, changing from negative (green colour) to positive (red colour), the highest increase being recorded between mature green and turning stages of ripening evolution which is related to the beginning of carotenoids synthesis. In the last three stages of ripening the colour lightness $\left(\mathrm{L}^{*}\right)$ decreased, indicating darkening of the tomato red colour. The lowest ratio of the red and green colour with a negative value $(-1.80)$ was recorded in the green fruits of the cultivar 'Cheramy' while the highest value of color parameter $\mathrm{a}^{*}$ (29.90) was recorded in completely ripened tomatoes of the same cultivar.

Chroma $\left(\mathrm{C}^{*}\right)$ is a color index representing the quantitative attribute of colorfulness, so that as $\mathrm{C}^{*}$ increases, color becomes more intense. Color chroma index $\left(\mathrm{C}^{*}\right)$ varied at different fruit ripeness stages of the investigated cultivars (Table 1 ). The lowest $\mathrm{C}^{*}$ value was detected in the green fruits of the cultivar 'Cheramy' while the highest chroma value was recorded in the tomatoes of the same cultivar at the deep-red stage.

Hue angle $\left(\mathrm{h}^{\circ}\right)$ of all investigated cultivars significantly decreased during ripening (Table 1). The analysed tomato cultivars developed a similar color at the deep-red stage, with average hue angles between 45 and 53 degrees. Considering the $\mathrm{a}^{*}$ to $\mathrm{b}^{*}$ ratio as a reference index for the ripening stage (Raffo et al. 2002; Batu, 2004), tomatoes of the investigated cultivars were classified in the light red maturity class $\left(0.65>a^{*} / b^{*}>0.95\right)$.
Correlations between lycopene content and color indexes have also been explored in this study. A significant negative correlation $(\mathrm{r}$ $=-0.521)$ was found between lycopene content and lightness $\left(\mathrm{L}^{*}\right)$, indicating that higher $\mathrm{L}^{*}$ values were related to lower lycopene content. Significant moderately strong positive correlations were found between lycopene content and $\mathrm{a}^{*}, \mathrm{~b}^{*}, \mathrm{a}^{*} / \mathrm{b}^{*}$ and chroma $\left(\mathrm{C}^{*}\right)$, proving once again that, in vine ripening conditions, these parameters could be used as objective ripening indexes (Arias et al., 2000). The strongest correlation was found between lycopene content and hue angle $\left(\mathrm{h}^{\circ}\right)(\mathrm{r}=-0.752)$ which is consistent with previous studies (Hertog et al, 2007). Besides, CIELab hue angle is the most commonly used parameter to indicate the development of red coloration during the ripening of tomato fruits (Pék et al., 2011). Correlation coefficients between main carotenoids content (lycopene $+\beta$-carotene) and each of the color indexes were found to be higher compared to those established in the correlations with lycopene.

\section{Conclusion}

Antioxidant compounds (lycopene, $\beta$-carotene, phenolics, flavonoids and ascorbic acid) and the hydrophilic antioxidant activity of fresh consumption tomato cultivars depend significantly on the cultivar and ripening stage. In all stages of ripening we have measured significantly higher lycopene, total phenolics, total flavonoids and ascobic acid content in the cherry type hybrid 'Cheramy' than in the large fruited cultivars 'Admiro' and 'Komet'. These results are due to the higher skin to volume ratio of cherry tomato fruits and to the higher levels of these compounds in the skin. The content of $\beta$-carotene increased constantly during ripening while lycopene content registered a sharp rise, especially in the last stage of ripening, when $47.2 \%$ of the lycopene content was accumulated. The patterns of variation of total phenolic content and antioxidant activity were quite similar during fruit ripening in all investigated cultivars. They increased during the first stages of ripening, reached maximum at the pink stage and declined significantly during the last two stages. Hydrophilic antioxidant activity showed significant moderately strong positive correlations with total phenolics and ascorbic acid while a stronger correlation was found between total phenolic content and ascorbic acid content in all cultivars. The analysis of CIELab color measurements revealed that the beginning of carotenoids synthesis is associated with a sharp increase of parameter $a^{*}$ while the ripening process is accompanied by the decrease of lightness and hue angle and the increase of Chroma $\left(\mathrm{C}^{*}\right)$ and $a^{*}$ to $b^{*}$ ratio. During ripening of tomato fruits significant moderately strong correlations were found between lycopene content and all color indexes but the strongest correlation was found with hue angle $(r=$ $-0.758)$.

\section{Acknowledgments}

We would like to thank Sere Popescu S.R.L. for providing the tomato samples for this study. This work benefited from the networking activities within the European funded COST ACTION FA1106 Quality Fruit. 


\section{References}

Adalid AM, Roselló S, Nuez F (2010). Evaluation and selection of tomato accessions (Solanum section Lycopersicon) for content of lycopene, $\beta$-carotene and ascorbic acid. Journal of Food Composition and Analysis 23(6):613-618.

Aghofack-Nguemezi J, Schwab W (2015). Differential accumulation of flavonoids by tomato (Solanum lycopersicum) fruits tissues during maturation and ripening. Journal of Applied Biosciences 84:7674 7681.

AOAC (2005). Official methods of analysis. Association of Official Analytical Chemists 15th Edition. In: Horwitz W, Latimer GW (Ed). AOAC International, Mariland, USA.

Arias R, Lee TC, Logendra L, James H (2000). Correlation of lycopene measured by HPLC with the $L^{*}, a^{*}, b^{*}$ color readings of a hydroponic tomato and the relationship of maturity with color and licopene content. Journal of Agricultural and Food Chemistry 48:1697-1702.

Batu A (2004). Determination of acceptable firmness and colour values of tomatoes. Journal of Food Engineering 61:471-475.

Cano A, Acosta M, Arnao MB (2003). Hydrophilic and lipophilic antioxidant activity changes during on-vine ripening of tomatoes (Lycopersicon esculentum Mill.). Postharvest Biology and Technology 28:59-65.

Domínguez E, Fernández MD, López Hernández JC, Pérez-Parra J, España L, Heredia A, Cuartero J (2012). Tomato fruit continues growing while ripening, affecting cuticle properties and cracking. Physiologia Plantarum 146:473-486.

Egea MI, Flores B, Sánchez-Bel P, Valdenegro M, Mártinez-Madrid MC, Romojaro F (2009). Factors influencing the evolution of the antioxidant compounds and the total antioxidant activity in fruits and vegetable products. Postharvest Technologies for Horticultural Crops, Research Signpost Publisher, Kerala, 2:121-138.

Fanasca S, Colla G, Maiani G, Venneria E, Rouphael Y, Azzini E, Saccardo F (2006). Changes in antioxidant content of tomato fruits in response to cultivar and nutrient solution composition. Journal of Agricultural and Food Chemistry 54:4319-4325.

Frenich AG, Torres MEH, Vega AB, Vidal JLM, Bolaños PP (2005). Determination of ascorbic acid and carotenoids in food commodities by liquid chromatography with mass spectrometry detection. Journal of Agricultural and Food Chemistry 53:73717376.

Garcia-Valverde V, Navarro-González I, García-Alonso J, Periago MJ (2013). Antioxidant bioactive compounds in selected industrial processing and fresh consumption tomato cultivars. Food and Bioprocess Technology 6(2):391-402.

Guil-Guerrero JL, Rebolloso-Fuentes MM (2009). Nutrient composition and antioxidant activity of eight tomato (Lycopersicon esculentum) varieties. Journal of Food Composition and Analysis 22:123-129.

Hdider C, Ilahy R, Tlili I, Lenucci MS, Dalessandro G (2013). Effect of the stage of maturity on the antioxidant content and antioxidant activity of high - pigment tomato cultivars grown in Italy. Food 7(1):1-7.
Helyes L, Lugasi A (2006). Formation of certain compounds having technological and nutritional importance in tomato fruits during maturation. Acta Alimentaria 35(2):183-193.

Hertog MLATM, Lammertyn J, Scheerlinck N, Nicolai BM (2007). The impact of biological variation on postharvest behaviour: The case of dynamic temperature conditions. Postharvest Biology and Technology 43:183-192.

Ilahy R, Hdider C, Lenucci MS, Tlili I, Dalessandro G (2011). Antioxidant activity and bioactive compound changes during fruit ripening of high-lycopene tomato cultivars. Journal of Food Composition and Analysis 24:588-595.

Kacjan-Maršić N, Gašperlin L, Abram V, Budič M, Vidrih R (2011). Quality parameters and total phenolic content in tomato fruits regarding cultivar and microclimatic conditions. Turkish Journal of Agriculture and Forestry 35:185-194.

Kotíková Z, Hejtmánková A, Lachman J (2009). Determination of the influence of variety and level of maturity on the content and development of carotenoids in tomatoes. Czech Journal of Food Science 27:S200-S203.

Kotíková Z, Lachman J, Hejtmánková A, Hejtmánková K (2011). Determination of antioxidant activity and antioxidant content in tomato varieties and evaluation of mutual interactions between antioxidants. LWT - Food Science and Technology 44:1703-1710.

Kuti JO, Konuru HB (2005). Effects of genotype and cultivation environment on lycopene content in red-ripe tomatoes. Journal of the Science of Food and Agriculture 85:2021-2026.

Lee J, Koo N, Min DB (2004). Reactive oxygen species, aging, and antioxidative nutraceuticals. Comprehensive Reviews in Food Science and Food Safety 3(1):21-33.

Martinez-Valverde I, Periago MJ, Provan G (2002). Phenolic compounds, lycopene and antioxidant activity in comercial varieties of tomato (Lyacopersicum esculentum). Journal of the Science of Food and Agriculture 82(3):323-330.

Mohammadzadeh S, Sharriatpanahi M, Hamedi M, Amanzadeh Y, Sadat Ebrahimi SE, Ostad SN (2007). Antioxidant power of Iranian propolis extract. Food Chemistry 103:729-733.

Nagata M, Yamashita I (1992). Simple method for simultaneous determination of chlorophyll and carotenoids in tomato fruit. Journal of the Japanese Society for Food Science and Technology 39:925-928.

Nour V, Trandafir I, Ionica ME (2014). Evolution of antioxidant activity and bioactive compounds in tomato (Lycopersicon esculentum Mill.) fruits during growth and ripening. Journal of Applied Botany and Food Quality 87:97-103.

Oliveira I, Sousa A, Ferreira ICFR, Bento A, Estevinho L, Pereira JA (2008). Total phenols, antioxidant potential and antimicrobial activity of walnut (Juglans regia L.) green husks. Food and Chemical Toxicology 46:2326-2331.

Opara UL, Al-Ani MR, Al-Rahbi NM (2012). Effect of fruit ripening stage on physico-chemical properties, nutritional composition and antioxidant components of tomato (Lycopersicum esculentum) cultivars. Food and Bioprocess Technology 5:3236-3243. 
412

Pék Z, Helyes L, Lugasi A (2010). Color changes and antioxidant content of vine and postharvest ripened tomato fruits. HortScience 45:466-468.

Pék Z, Szuvandzsiev P, Nemenyi A, Helyes L (2011). The effect of natural light on changes in antioxidant content and color parameters of vine-ripened tomato (Solanum lycopersicum L.) fruits. HortScience 46(4):583-585.

Periago MJ, García-Alonso J, Jakob K, Olivares AB, Bernal MJ, Iniesta MD, Martinez C, Ros G (2009). Bioactive compounds, folates and antioxidant properties of tomatoes (Lycopersicum esculentum) during vine ripening. International Journal of Food Science and Nutrition 60(8):694-708.

Perveen R, Suleria HA, Anjum FM, Butt MS, Pasha I, Ahmad S (2015). Tomato (Solanum lycopersicum) carotenoids and lycopenes chemistry; metabolism, absorption, nutrition, and allied health claims - A comprehensive review. Critical Reviews in Food Science and Nutrition 55(7):919-29.

Radzevičius A, Karklelienė R, Viškelis P, Bobinas Č, Bobinaite R, Sakalauskienè S (2009). Tomato (Lycopersicon esculentum Mill.) fruit quality and physiological parameters at different ripening stages of Lithuanian cultivars. Agronomy Research 7(2):S712-S718.

Raffo A, Leonardi C, Fogliano V, Ambrosino P, Salucci M, Gennaro L, Bugianesi R, Giuffrida F, Quaglia G (2002). Nutritional value of cherry tomatoes (Lycopersicon esculentum cv Naomi F1) harvested at different ripening stages. Journal of Agricultural and Food Chemistry 50:6550-6556.

Singleton VL, Rossi JA (1965) Colorimetry of total phenolics with phosphomolybdic-phosphotungstic acid reagents. American Journal of Enology and Viticulture 16:144-158.
Sgherri C, Cecconami S, Pinzino C, Navari-Izzo F, Izzo R (2010). Levels of antioxidants and nutraceuticals in basil grown in hydroponics and soil. Food Chemistry 123:416-422.

Stewart AJ, Bozonnet S, Mullen W, Jenkins GI, Lean MEJ, Crozier A (2000). Occurrence of flavonols in tomatoes and tomato-based products. Journal of Agricultural and Food Chemistry 48:2663-2669.

Thompson KA, Marshall MR, Sims CA, Wei CI, Sargent SA, Scott JW (2000). Cultivar, maturity, and heat treatment on lycopene content in tomatoes. Journal of Food Science 65(5):791-795.

Vinha AF, Alves RC, Barreira SVP, Castro A, Costa ASG, Oliveira MBPP (2014). Effect of peel and seed removal on the nutritional value and antioxidant activity of tomato (Lycopersicon esculentum L.) fruits. LWT - Food Science and Technology 55:197-202.

Viuda-Martos M, Sanchez-Zapata E, Sayas-Barberá E, Sendra E, Pérez-Álvarez JA, Fernández-López J (2014). Tomato and tomato byproducts. Human health benefits of lycopene and its application to meat products: a review. Critical Reviews in Food Science and Nutrition 54(8):1032-1049.

Wold AB, Rosenfeld HJ, Holte K, Baugerød H, Blomhoff R, Haffner K (2004). Colour of post-harvest ripened and vine ripened tomatoes (Lycopersicon esculentum Mill.) as related to total antioxidant capacity and chemical composition. International Journal of Food Science and Technology 39:295-302.

Yamaguchi M (1983). Solanaceous fruits: Tomato, eggplant, peppers and others. In: Yamaguchi M (Ed). World vegetables. AVI Book, New York pp 291-312. 